\title{
Moisture problems of functional joints of wooden windows - causes analysis
}

\author{
Adela Palková, ${ }^{1 *}$, Milan Palko ${ }^{1}$, and Peter Buday ${ }^{1}$ \\ ${ }^{1}$ Department of Building Constructions, Slovak University of Technology in Bratislava, Faculty of \\ Civil Engineering, Radlinského 11, 81005 Bratislava, Slovakia
}

\begin{abstract}
The article addresses the issue of the humidity regimen of a functional wooden window joint. Current energy-saving trends in the buildings bring secondary effects associated with indoor climate change. Increase of the thermal-technical quantification, non-breathability, and diffusion resistance of the building envelope without the solution of controlled ventilation brings an extreme rise of the interior moisture. The passage of moisture through a functional joint is ensured mainly by exfiltration. The energy standard applicable after the year 2020 assumes buildings with almost zero energy need that cannot be reached without a recuperation system. The concept of the recuperation systems usually works as a pressure system, which increases the likelihood of exfiltration. Measurements done in a large climate chamber show that the diffusion of water vapor can overcome the infiltration flow of the outside air. The passage of moisture results in icing or condensation in the functional joint, which subsequently damages the surface treatment of the wood. Another serious defect is the subsequent mold growth.
\end{abstract}

\section{Introduction}

The problem of moisture transmission in gaps (leakages) in building envelopes is not a newly discovered issue. The moisture penetration through leakages in building envelopes has been investigated mainly in relation to slab blocks development. The leakages due to imperfect structural design and materials applied in roof envelopes formed another area for investigation. In our country, Prof. Ing. František Mrlík, DrSc. has dealt with research and moisture transmission in gaps of building envelopes [1]. Prof. Dr.Ing Gerd Hauser dealt with the similar problem area: moisture transmission through gaps, mainly for wooden houses in Germany [2]. While solving these problems the window structures were at a relatively low development level and had high leakage in terms of air infiltration and exfiltration. Due to these window characteristics as well as low requirements in energy efficiency field the relative humidity in buildings used to be approximately $30 \%$ [3]. By improving the thermal characteristics of building structures in relation to energy the relative air humidity has increased up to 50\%, which is also given in STN 730540 [4 - 6]. Taking into consideration the change of boundary conditions and characteristics of window

\footnotetext{
*Corresponding author: adela.palkova@stuba.sk
} 
structures the problem of water vapour condensation in functional gap between casement and window frame has occurred.

\section{Moisture formation and transport}

Indoor relative humidity is dependent on a number of factors, such as ventilation, vapour barrier in constructions, the ability to accept and deliver moisture and the source of moisture. Figure 1 shows a relative humidity graph in the living room for six model variants (processed in EnergyPlus). Variant 1 - basic alternative - gap permeability all windows is determined by the value of $0.0002 \mathrm{~kg} /(\mathrm{s} . \mathrm{m} . \mathrm{Pa})$, inner door $0.005 \mathrm{~kg} /(\mathrm{s} . \mathrm{m} . \mathrm{Pa})$ and exterior door $0.001 \mathrm{~kg} /(\mathrm{s} . \mathrm{m} . \mathrm{Pa})$, the evaluation sleeping zone are defined by two people daily from 23:00 to 07:00, the room is tempered to $+20.0^{\circ} \mathrm{C}$. Room is oriented to the $\mathrm{SW}$. Variant 2 - difference compared to the original alternative of variant 1 is in doubling the gap permeability of windows to $0.0002 \mathrm{~kg} /(\mathrm{s} . \mathrm{m} . \mathrm{Pa})$. Variant 3 - difference versus the original alternative of variant 1 is to remove, exclude humidity producers - people, model without counting people. Variant 4 - difference versus the original alternative variant 1 is the addition of morning and evening intensive ventilation of the room at the level of air exchange $\mathrm{n}=3.0 \mathrm{l} / \mathrm{h}$ in the duration of 15 minutes, both in the morning and in the evening. Variant 5 - difference versus the original alternative of variant 1 is to complement the morning and evening intensive ventilation of the room at the level of the air exchange $\mathrm{n}=3.0 \mathrm{1} / \mathrm{h}$ in a duration of 30 minutes, both morning and evening. Variant 6 - differentiation from the original alternative of variants 1 is the addition of morning and evening intensive ventilation of the room at the level of air exchange $n=3.0 \mathrm{l} / \mathrm{h}$ in the duration of 60 minutes, both in the morning and in the evening.

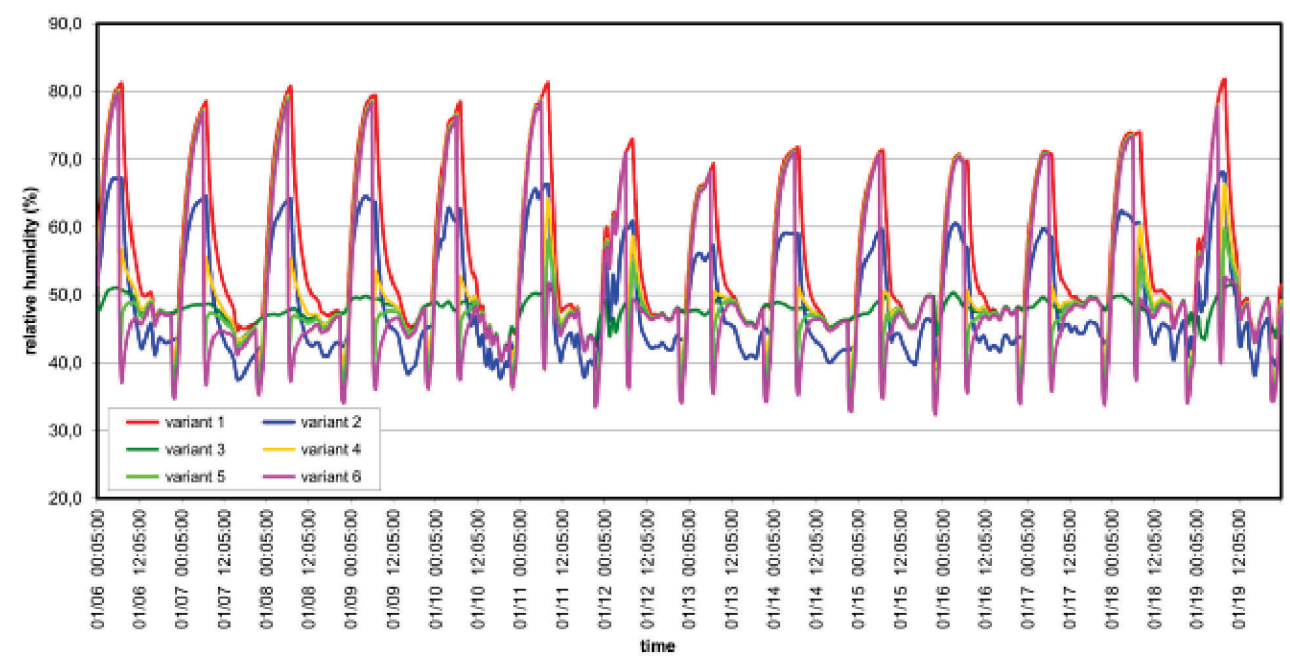

Fig. 1. Graph of relative humidity in the living room during 06.01. - 19.01.

Variants describe the real functioning of the existing buildings without the recuperation assembly. The values in the chart were determined to perform laboratory measurements on profile systems. The condensate generation in functional gap (see Figure 2 and Figure 3 ) is not described neither limited by the standards nor regulations. Seriousness of the problem varies depending on the material base. Considering the wooden window structures the degradation of surface finish occur and its thermal characteristics change. 


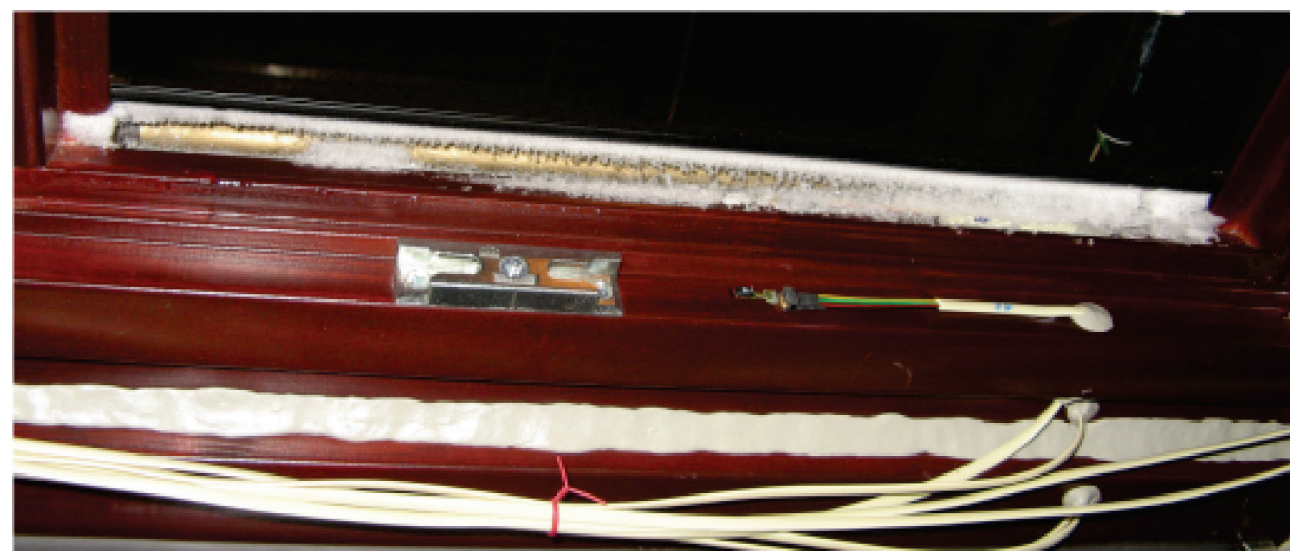

Fig. 2. Demonstration of ice coating and condensation in gap between casement and window frame at exfiltration and $200 \mathrm{~Pa}$ pressure difference (lower part).

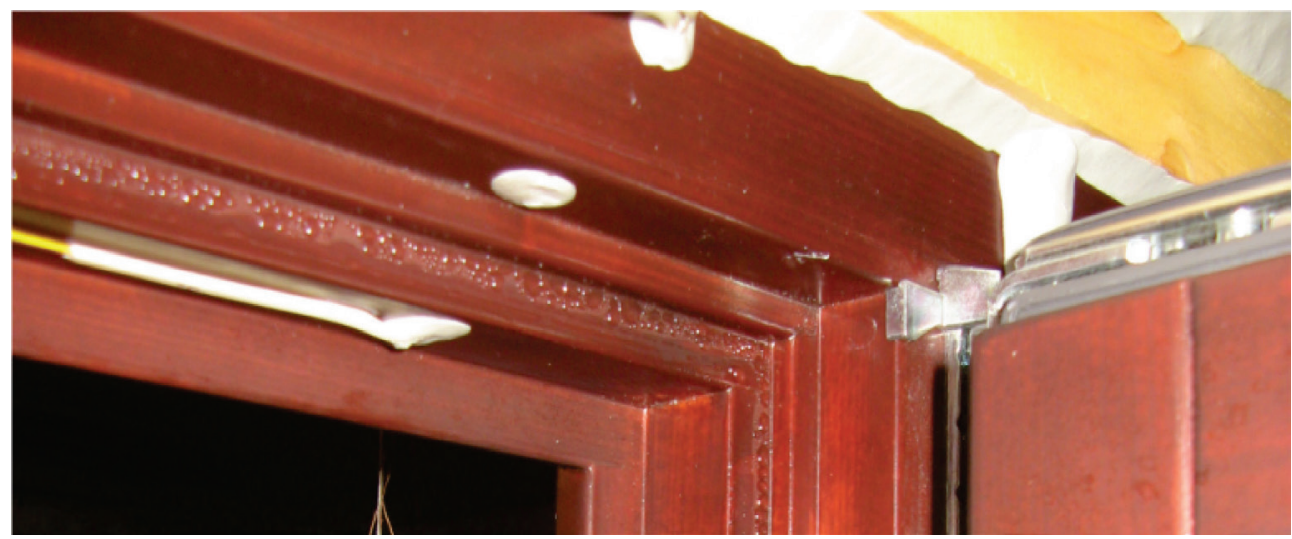

Fig. 3. Demonstration of condensation in gap between casement and window frame at exfiltration and $200 \mathrm{~Pa}$ pressure difference (upper part).

The moisture transport through gap between casement and window frame at condensation temperature is the main cause of condensation of water vapour. The transport causes (see Figure 4):

- Air pressure differences (taking water vapour) - infiltration a exfiltration,

- Diffusion of water vapour (different saturation of water vapour in exterior and indoor air).

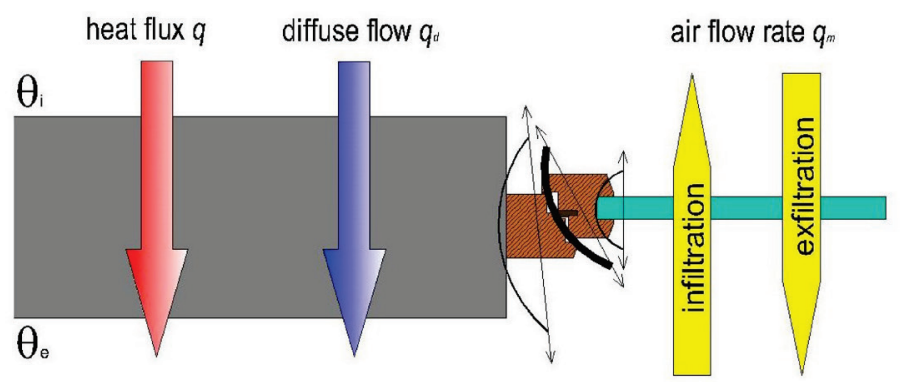

winter

Fig. 4. Schematic representation of heat transmission, diffusion of water vapour and airflow through window structure $[7,8]$. 


\section{Laboratory measurements}

The experimental measurements were carried out in heat engineering laboratories at the Faculty of Civil Engineering. Measurement models represent real window structures. The big climatic chamber illustrated in Figure 5 was used at measurements. The chamber A represents exterior climate (outdoor temperature $-11^{\circ} \mathrm{C}$, pressure difference between exterior and interior from 0 to $2000 \mathrm{~Pa}$, heat transfer coefficient $25 \mathrm{~W} / \mathrm{m}^{2} \mathrm{~K}$, relative humidity $50 \%$ ). The chamber B represents balancing chamber for HOT-BOX and simulate the indoor climate (indoor temperature $+20^{\circ} \mathrm{C}$, relative humidity $50 \%$ ). The HOT-BOX is used for measurement of heat transmission using measured element simulating the indoor conditions (indoor temperature $+20^{\circ} \mathrm{C}$, relative humidity $50 \%$, heat transfer coefficient 7.7 $\mathrm{W} / \mathrm{m}^{2} \mathrm{~K}$ ). Part $\mathrm{D}$ is a masking panel, in which the measured window structure is imbedded. In case of our measurement the HOT-BOX was not used as the conditions with infiltration or exfiltration were to be investigated.

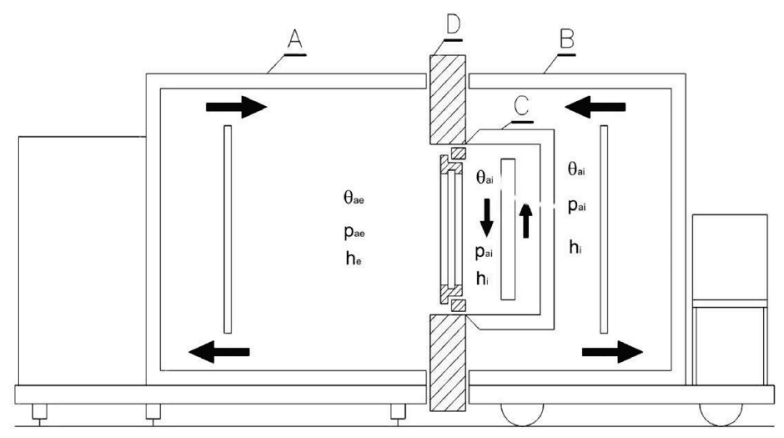

Fig. 5. Scheme of laboratory equipment of big climatic chamber [9].
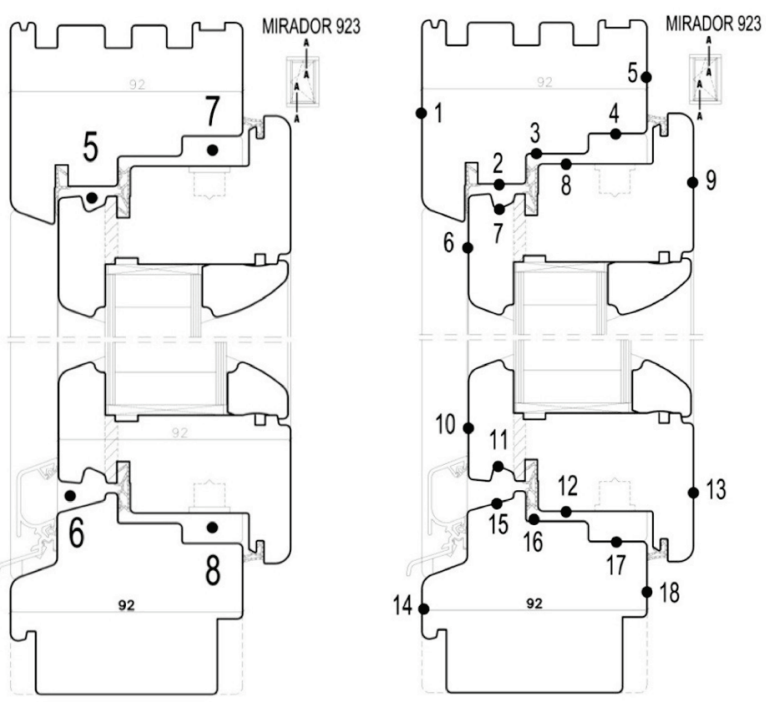

Fig. 6. Geometric parameters of window profiles and placement of measurement sensors.

Measurement sensors are divided into two groups. The first group measures the surface temperatures (PT 100). The second one measures the temperatures and relative air humidity (SHT 75). The sensors distribution is presented in Figure 6. 


\section{Results and discussion}

At experimental measurements in big climatic chamber the occurrence and amount of water vapour and ice coating condensate was found out after each completed measurement phase. The internal surface temperatures and air temperature including relative air humidity in gap measurement points (see Figure 6) belonged into the second valuation data group. The measured values are presented in Figure 7.

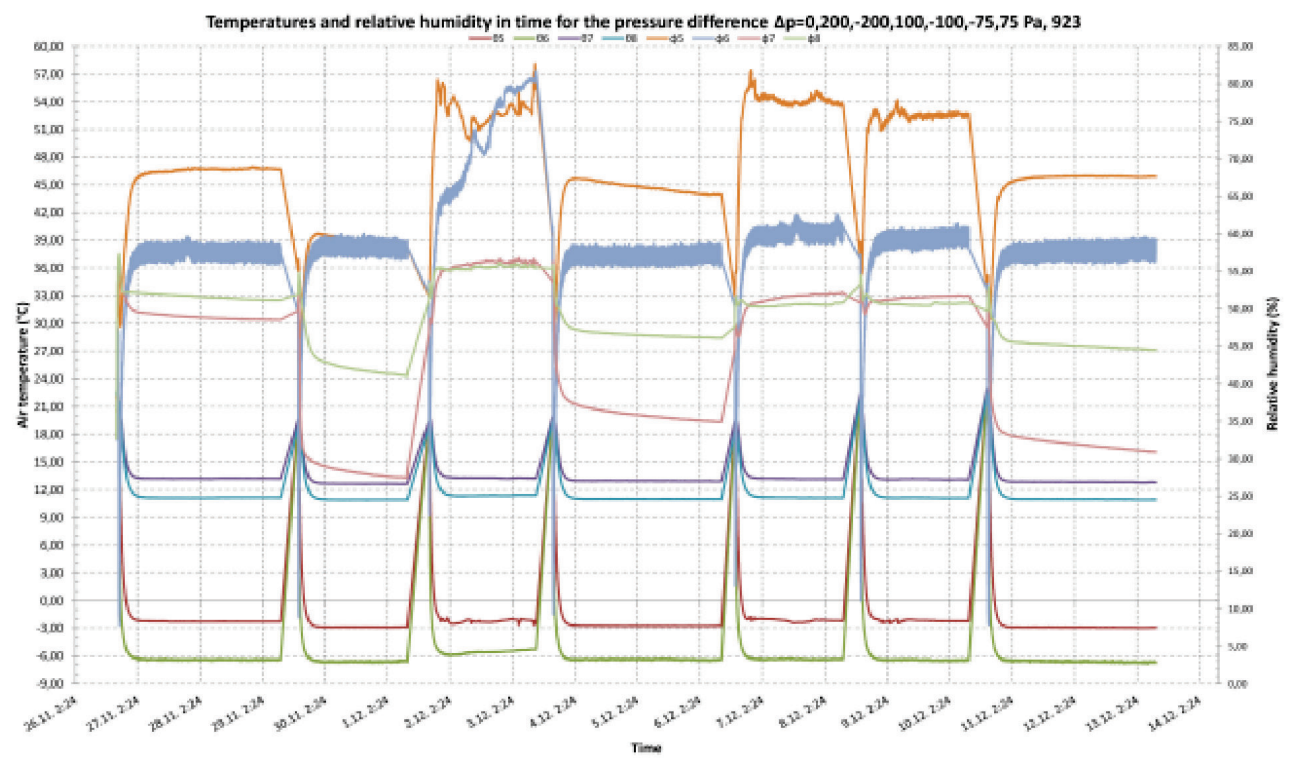

Fig. 7. Graph of temperatures and relative humidity in time for the pressure difference.

In research works carried out by Prof. Ing. František Mrlík, DrSc and Prof. Dr. Ing. Gerda Hauser on building envelope gap and joint characteristics as well as research works on windows (Dipl. Ing. Konrad Huber) it has been proofed that water vapour transported through building envelope causes problems $[1,2]$. The results obtained in our research broaden and supplement the above given investigation works providing more comprehensive and more detailed knowledge of environmental physics bringing about water vapour condensation in functional gap between casement and window frame.

\section{Conclusions}

At an initial investigation stage it was known that condensation originated only in equilibrium state and at different pressure impact causing the exfiltration. However, it was found out during the measurements that the condensation also originates due to the infiltration. The condensation boundary for water vapour was being finding after the correct set up of circuit forging and, thus, also the sealing compression. After the measurements the value of differences of pressures between cool and warm chamber at which the condensate formation stops in the range 60 to $75 \mathrm{~Pa}$. Interestingly, the condensation of water vapor in a functional gap improves the acoustic properties $[10,11]$.

This research was supported by Scientific Grant Agency MŠVVŠ SR and SAV under VEGA 1/0685/16. This research was also supported by Apol, s.r.o. 


\section{References}

1. F. Mrlík, Moisture problems of building materials and structures (Alfa press, Bratislava, 1985)

2. G. Hauser, Ch. Kempkes, Der Einfluss von windinduzierten Druckschwankungen auf das thermisch-hygrische Verhalten von durchstromten Leckagen (Kassel, 2005)

3. I. Chmúrny, Thermal protection of buildings (Jaga group, Bratislava, 2003)

4. P. Oravec, AMR 899, 184-187 (2014)

5. P. Oravec, Procedia Manufacturing 2, 348-352 (2015).

6. STN 73 0540-2 Thermal performance of buildings and components. Thermal protection of buildings. Part 2: Functional requirements (2012)

7. EN ISO 10077-2 Thermal performance of windows, doors and shurtters - Calculation of thermal transmittance - Part 2: Numerical method for frames (ISO/DIS 10077-2: 1998)

8. A. Palková, M. Palko, Condensation of water vapor in the window structure. Proceedings of the Conference ANSYS 2010 (Frymburk, 2010)

9. A. Palková, M. Palko, A. Puškár, Proceedings of the 5. International conference. Buildings and environment 2010, 204-209 (Brno, 2010)

10. D. Dlhý, AMR 855, 233-236 (2014)

11. D. Dlhý, ATF 2013:2nd Conference on Acoustics, Light and Thermal Physics in Architecture and Building Structures, 21-24 (2013) 